\section{A routine for the computation of an orthomax solution and its associated orthomax orthonormal}

\author{
RICHARD J. HOFMANN \\ Miami University, Oxford, Ohio 45056
}

A number of different attempts to solve the rotation problem in factor analysis have resulted in a variety of analytic orthogonal transformation criteria. Many of these criteria are summarized by either Gorsuch (1974) or Mulaik (1972) and are referred to within a general framework as either the orthomax or transvarimax criterion. Although three specific criteria, the varimax, the equamax, and the quartimax have been utilized for a number of years, there exists an infinite number of other specific criteria within the orthomax framework having relatively unknown characteristics and properties.

Let $F$ be some nxr factor matrix and let $T$ be some $\mathrm{IXI}$ orthonormal transformation matrix determined from $F$ such that FT maximizes some specific form of the orthomax criterion. Let $A=$ FT and then define the general orthomax criterion such that

$$
\text { Orthomax Value }=\sum_{j=1}^{x}\left[\frac{n \sum_{i=1}^{n}\left(a_{j}^{z}\right)^{2}-\gamma\left(\sum_{i=1}^{n} a_{j}^{2}\right)^{2}}{n^{2}}\right] \text {. }
$$

Maximizing the orthomax value with $(\gamma=1)$ will define the varimax criterion, with $(\gamma=r / 2)$ the equamax criterion, with $(\gamma=0)$ the quartimax criterion. If the variables are normalized during the maximization process, then the resulting transformation solution is referred to as a "normal" solution; otherwise, it is referred to as a "raw" solution. Any value may be chosen for $\gamma$, but little is presently known about the properties of the resulting solutions.

The general orthomax routine is written to maximize the orthomax criterion, regardless of choice for $\gamma$, utilizing a series of single plane transformations, that is, Factors 1 and 2 are rotated, and then Factors 1 and 3 , and so on, to factors $(r-1)$ and (r). Such a series of single plane rotations is referred to as a cycle. Although the routine is written for a maximum of 75 cycles, the cycles are also terminated when the specific orthomax criterion stabilizes to four decimals, which usually occurs in less than 75 cycles.

Two matrices are determined by the routine, $A$, the orthomax transformation solution, and, $T$, the specific orthomax orthonormal matrix utilized with $\mathrm{F}$ such that $\mathrm{A}=\mathrm{FT}$. The two solution matrices are defined for a single cycle as

$$
\begin{gathered}
\mathrm{T}=\mathrm{IT}_{1} \mathrm{~T}_{2} \mathrm{~T}_{3} \ldots \mathrm{T}_{(\mathrm{r}-1) \mathrm{r}} ; \\
\mathrm{A}=\mathrm{FT}=\mathrm{FT}_{1} \mathrm{~T}_{2} \mathrm{~T}_{3} \ldots \mathrm{T}_{(\mathrm{r}-1) \mathrm{r}},
\end{gathered}
$$

where the subscript refers to the particular planar rotation, and I is the identity matrix.

Input. Three input parameters are necessary for this program, the unrotated factor matrix $F$, a value for $\gamma$, and a binary coding to signify either a raw or a normal transformation solution.

Output. Program output includes the orthomax transformation solution, the particular orthomax orthonormal, $\mathrm{T}$, and the communality estimates.

Capacity. The program requires 2,892 bytes of core on the IBM Model 370-168 G-level compiler as it is presently written. The routine is programmed in FORTRAN IV, utilizing double precision, single subscripting, and principles of dy namic storage. As such, there are no practical limits on either the number of variables or the number of factors that may be input into the program. This program has also been run on certain RCA, CDC, and UNIVAC models.

Availability. Copies of this paper, a source listing, and documented output from an illustrative example can be obtained free of charge by writing to Richard J. Hofmann, Department of Educational Psychology, Miami University, Oxford, Ohio 45056.

\section{REFERENCES}

Gorsuch, R. Factor analy sis. Philadelphia: Saunders, 1974. Mulaik, S. The foundations of factor analysis. New York: McGraw-Hill, 1972 